\title{
IN-HOSPITAL EARLY COMPLICATIONS IN DIABETICS VS NON DIABETICS WITH ACUTE ST ELEVATION MYOCARDIAL INFARCTION AGE GROUP 30-70 YEARS
}

\author{
Gul Khan, Imtiaz Ahmed Khan, Fahad Ahmad Khan*, Shaheer Farhan, Javeria Kamran, Anam Fatima Janjua, Naseer \\ Ahmed Samore, Sadaf Khan**, Sohail Aziz, Abdul Hameed Siddiqui
}

Armed Forces Institute of Cardiology/National Institute of Heart Disease (AFIC/NIHD)/National University of Medical Sciences (NUMS) Rawalpindi Pakistan, *Pak Emirates Military Hospital/National University of Medical Sciences (NUMS) Rawalpindi Pakistan, **Nishter Hospital Multan Pakistan

\begin{abstract}
Objective: To determine in hospital early complications in diabetics' vs non diabetics with acute ST elevation myocardial infarction.

Study Design: Comparative cross-sectional study.

Place and Duration of Study: The study was conducted in emergency departments and adult cardiology wards of Armed Forces Institute of Cardiology/National Institute of Heart Diseases, from Aug to Nov 2019.

Methodology: A comparative cross sectional study was conducted on 380 patients (190 patients with diabetes and 190 patients without diabetes) who presented with acute ST-Elevation MI in age group 30 to 70 years to emergency department of Armed Forces Institute of Cardiology/National Institute of Heart Disease during specified period. Patients with rescue PCI and new onset of LBBB were also included. Patients with age group lesser than 30 years or greater than 70 years with STEMI were excluded. Sampled with consecutive non probability technique in patients was assessed with ECG, cardiac enzymes, transthoracic echocardiography, renal Doppler and RFTs. All patients were admitted in wards and were followed up during hospital stay. Patients were evaluated and their record of Primary PCI and thrombolysis was also noted. Data was entered and analyzed with SPSS-23.

Results: A total of 380 patients with STEMI were included in this study consisting of 292 (76.8\%) male and 88 (23.1\%) female from 30 to 70 years. The patients were divided in two groups i.e. diabetic and non-diabetic, 190 patients were included in each group. It was found that frequency of ST-Elevation MI was higher in diabetic group as compared to non-diabetic group. All the patients were analyzed for complications occurred after STElevation MI. LV failure, Brady arrhythmias, atrial fibrillation, post MI angina and cardiogenic shock were the main complications noted. It was found that all these complications are more in diabetic group post MI angina which occurred most frequently in non-diabetic group.

Conclusion: In our study we observed that left ventricular failure and arrhythmias were the major complications. Mortality was higher in diabetic patients than non-diabetic patients. In both groups PPCI and SK reduced mortality. Post MI angina were found more frequent in non-diabetic group.
\end{abstract}

Keywords: Complications, Diabetic, In hospital, Mortality, Non-diabetic, Streptokinase.

\footnotetext{
This is an Open Access article distributed under the terms of the Creative Commons Attribution License (http://creativecommons.org/licenses/by/4.0), which permits unrestricted use, distribution, and reproduction in any medium, provided the original work is properly cited.
}

\section{INTRODUCTION}

Acute Myocardial Infarction (AMI) can be considered as a potential epidemic for mankind 1 . The incidence of coronary artery disease is rising in Pakistan ${ }^{1}$. The acute coronary syndrome includes unstable angina, non-ST segment elevation MI (NSTEMI) and ST segment elevation MI $(\mathrm{STEMI})^{2}$. Diabetes mellitus is one of the six primary risk factors identified for $\mathrm{MI}^{3}$, others being dyslipidemia, smoking, male gender, hyperten-

Correspondence: Dr Gul Khan, Department of Cardiology, AFIC/NIHD Rawalpindi Pakistan sion and family history of atherosclerotic arterial disease $^{1,4}$. Diabetes mellitus is a metabolic disor0der which increases the rate of atherosclerosis progression of vascular occlusion ${ }^{4}$. Even after prompt PPCI and thrombolysis the after-math of diabetic patients is still worse than the non-diabetics, indicating post $\mathrm{PCI}$ and post thrombolysis impaired left ventricular function and prognosis 5 . The aim of PCI and thrombolysis in acute MI is early and complete myocardial reperfusion. Incomplete or failed reperfusion is associated with increased risk of complications ${ }^{6}$. Analysis of STsegment resolution on ECG, after fibrinolytic 
therapy, in cases of ST elevation myocardial Infarction offers an attractive and cost effective solution to assess coronary reperfusion?. Whereas coronary angiogram is a marker for epicardial reperfusion, ST segment resolution offers a better reflection of micro vascular reperfusion ${ }^{8}$. Although successful PCI and thrombolysis of the epicardial vessel is necessary for good prognosis, but the micro-vascular flow more strongly correlates with the outcome ${ }^{9}$. ST segment is therefore a better indicator of prognosis, and provides information, which cannot be assessed on basis of coronary angiogram alone ${ }^{10}$. In fact Schroeder et al reported that absence of ST segment resolution was the most powerful independent predictor of early mortality $(p=0.0001)^{6}$. ST resolution can also be used as a tool to identify candidates for early invasive procedures such as PTCA, who are at risk of developing complications because of nonresolution of ST segment after initial thrombolytic therapy. Since ECG is widely available even in developing nations, it is important to establish its effectiveness as a tool for assessing reperfusion as it will offer the cheapest alternative for assessing recovery and myocardial salvage ${ }^{11}$.

The aim of our study was to correlate the incidence of complications with diabetes by using ST segment resolution as a tool, thereby reenforcing the role of incomplete ST-resolution as a marker of worse clinical outcome in cases of diabetes with ST-elevated myocardial Infarction in our population. The purpose of this study was to document the complications especially the MACE (major Adverse Cardiovascular Events) and other complications in diabetic and non-diabetic patients after acute ST elevation myocardial infarction in age group from 30 year to 70 years in our institution.

\section{METHODOLOGY}

A comparative cross sectional study was conducted on 380 patients (190 patients with diabetes and 190 patients without diabetics) who presented with Acute ST-Elevation MI in age group 30 to 70 years to emergency department of Armed Forces Institute of Cardiology/National
Institute of Heart Disease during specified period. Mean age was $53.34 \pm 8.38$ years as shown in table-I. Patients with rescue PCI and new onset of LBBB were also included. Patients with STEMI age lesser than 30 years or greater than 70 years and patients who has ST elevation due to other reasons like early repolarization, LV hypertrophy, Brugada syndrome and hyperkalemia were excluded. Patients presented with non ST elevation MI and unstable angina were also excluded. Acute ST elevation MI was considered on ECG by ST elevation of $1 \mathrm{~mm}$ or more in two or more than two contiguous leads, often with reciprocal ST depression in the contra lateral leads. In lead V2 to V3 ST segment elevation of at least $2 \mathrm{~mm}$ in men older than 40 years and $2.5 \mathrm{~mm}$ in men younger than 40 years, and $1.5 \mathrm{~mm}$ in women was taken as significant for acute STEMI22,24.

Sample with consecutive non probability technique were taken and patients were assessed with ECG, cardiac enzymes, transthoracic echocardiography, renal Doppler and RFTs. All patients were admitted in wards and were followed up during hospital stay. Patients were evaluated and history of Primary PCI and thrombolysis was also noted. Data was entered and analyzed with SPSS-23.

Continuous variables were expressed as mean, standard deviation (SD) and qualitative data were presented as percentage and frequencies. Chi-square test was used to determine any significant difference between two groups. A $p$ value of less than 0.05 was considered significant. The statistical analysis was performed with SPSS software.

\section{RESULTS}

A total of 380 patients with STEMI were included in this study consisting of 292 (76.8\%) male and $88(23.2 \%)$ females from 30 to 70 years. The patients were divided in two groups i.e. diabetic and non-diabetic, 190 patients were included in each group as shown in table-I. All the patients were analyzed for in hospital early complications between the two groups on the basis of ECG finding, cardiac enzymes, Trans- 
thoracic echocardiography, renal doppler and RFTs. It was found that patients treated with primary PCI or Streptokinase the mortality was
Patients who were not treated with PPCI or SK in non-diabetic group mortality was $3(16.6 \%)$ while in diabetic group mortality was $4(18.1 \%)$

Table-I: Demographic data at the time of presentation.

\begin{tabular}{l|c|c|c|c}
\hline Demographic characteristics & Sample size 190 Non Diabetic & \multicolumn{2}{c}{ Sample size 190 Diabetic } \\
\hline Frequency and Percentage & Frequency & Percentage & Frequency & Percentage \\
\hline Mean \pm Age & \multicolumn{4}{c}{$53.34 \pm 8.38$} \\
\hline Gender & 160 & $84.14 \%$ & 146 & $76.6 \%$ \\
\hline Male & 30 & $15.9 \%$ & 44 & $23.4 \%$ \\
\hline Female & 36 & $18.2 \%$ & 28 & $14.9 \%$ \\
\hline Family History & 95 & $50 \%$ & 85 & $44.7 \%$ \\
\hline Smoker or ex-smoker
\end{tabular}

Table-II: Age wise distribution of STEMI from 30 to 70 year.

\begin{tabular}{l|c|c|c|c}
\hline \multirow{2}{*}{ Age wise Distribution } & \multicolumn{2}{|c|}{ Non Diabetic } & \multicolumn{2}{c}{ Diabetic } \\
\cline { 2 - 5 } & Frequency & Percentage & Frequency & Percentage \\
\hline 30 to 40 years & 06 & $3.1 \%$ & 07 & $3.7 \%$ \\
\hline 41 to 50 years & 22 & $11.6 \%$ & 30 & $15.7 \%$ \\
\hline 51 to 60 years & 68 & $35.8 \%$ & 81 & $42.6 \%$ \\
\hline 61 to 70 years & 94 & $49.5 \%$ & 72 & $37.9 \%$ \\
\hline
\end{tabular}

Table-III: Comparison of complications in diabetic vs non diabetic patient after STEMI.

\begin{tabular}{|c|c|c|c|c|}
\hline \multirow{2}{*}{$\begin{array}{l}\text { Parameter } \\
\text { 1.Mechinical }\end{array}$} & \multicolumn{2}{|c|}{ Non diabetic } & \multicolumn{2}{|c|}{ Diabetic } \\
\hline & Frequency & Percentage & Frequency & Percentage \\
\hline VSR & 1 & $0.5 \%$ & 3 & $1.57 \%$ \\
\hline Acute MR & 2 & $1.05 \%$ & 4 & $2.1 \%$ \\
\hline Ventricular anurysem & - & - & 1 & $0.5 \%$ \\
\hline LV failure & 24 & $12.98 \%$ & 40 & $21.05 \%$ \\
\hline RV failure & 8 & $4.2 \%$ & 12 & $6.3 \%$ \\
\hline \multicolumn{5}{|l|}{$\begin{array}{l}\text { 2. Arrythmias } \\
\text { a.Bradyarrythmias }\end{array}$} \\
\hline 1st degree AV block & 23 & $12.1 \%$ & 31 & $16.3 \%$ \\
\hline 2nd degree AV block (mobits 1) & 13 & $6.8 \%$ & 21 & $11.05 \%$ \\
\hline 2nd degree AV block (mobits 2) & 2 & $1.05 \%$ & 4 & $2.1 \%$ \\
\hline 3rd degree AV block & 8 & $4.2 \%$ & 14 & $7.36 \%$ \\
\hline SND & 19 & $10 \%$ & 27 & $14.2 \%$ \\
\hline LBBB & 2 & $1.05 \%$ & 3 & $1.57 \%$ \\
\hline \multicolumn{5}{|l|}{ b.Tachyarrythmias } \\
\hline SVT & 4 & $2.1 \%$ & 5 & $2.63 \%$ \\
\hline a.Flutter & 2 & $1.05 \%$ & 2 & $1.05 \%$ \\
\hline a.Fibrillation & 18 & $9.47 \%$ & 23 & $12.10 \%$ \\
\hline \multicolumn{5}{|l|}{ 3.Others complications } \\
\hline Early pericarditis & 9 & $4.76 \%$ & 11 & $5.8 \%$ \\
\hline Cardiogenic shock & 17 & $8.9 \%$ & 22 & $11.5 \%$ \\
\hline Post mi angina & 41 & $21.6 \%$ & 36 & $18.9 \%$ \\
\hline Death & 6 & $3.1 \%$ & 9 & $4.7 \%$ \\
\hline
\end{tabular}

p-value $=0.05$

lesser than those not treated with PPCI or streptokinase (non-diabetic group mortality was $1.74 \%$ while in Diabetic group mortality was $2.97 \%$ ). as shown in table-IV. It was also found that frequency of ST-Elevation MI is higher in diabetic group as compared to non-diabetic group. All the 
patients were analyzed for complications occurred after ST-Elevation MI. LV failure, Brady arrhythmias, atrial fibrillation, post MI angina and cardiogenic shock were the main complications noted. It was found that all these complications are more in diabetic group except ventricular tachycardia and post MI anginawhich occurred most frequently in non-diabetic group. LV failure in another study abroad (27\%) ${ }^{13}$. This difference in percentage compared with a local study from Karachi can be related with the status of diabetes and its management in different areas of the country ${ }^{14-16}$. In age group 30-40 in greater percentage of diabetic patients were presented with STEMI as compared to non-diabetic group which shows that MI is not only common in advance

Table-IV: Comparison of mortality in diabetic vs non diabetic patients admitted with stemi with and without PPCI or streptokinase.

\begin{tabular}{l|c|c|c|c}
\hline & $\begin{array}{c}\text { Non Diabetic } \\
\mathbf{1 9 0} \text { patients }\end{array}$ & Mortality & $\begin{array}{c}\text { Diabetic } \\
\mathbf{1 9 0} \text { patients }\end{array}$ & Mortality \\
\hline Treated With PPCI OR SK & 172 & $3(1.74 \%)$ & 168 & $5(2.97 \%)$ \\
\hline Not Treated With PPCI or SK & 18 & $3(16.6 \%)$ & 22 & $4(18.1 \%)$ \\
\hline Total & 190 & $6(3.15 \%)$ & 190 & $9(4.7 \%)$ \\
\hline
\end{tabular}

diabetic patients was $21 \%$ while in non-diabetic group it was $12.9 \%$. Among Brady arrhythmias first and second degree AV blocks were found more frequently in diabetic group that is $16.3 \%$ and $11 \%$ respectively. Among tachyarrhythmias atrial fibrillation was found more frequent in diabetic group $12 \%$ as compared to non-diabetic group that is $9.47 \%$. Other complications including early pericarditis and cardiogenic shock were found more frequent in diabetic group while post MI angina happened more often in non-diabetic group that is $41(21.57 \%)$ as compared to diabetic group that is $36(18.9 \%)$. All these details have been shown in table-III. Similarly mortality was also higher in diabetic group that is $9(4.7 \%)$ than nondiabetic group that is $6(3.15 \%)$ as shown in table-IV.

\section{DISCUSSION}

A total of 380 patients with STEMI were investigated in this study out of which 160 (42.1\%) were male and $30(7.9 \%)$ were female. Mean age was $53.34 \pm 8.38$ years. The demographic characteristic of the study population were showing no significant difference. Out of 190 nondiabetic patients, $160(84.14 \%)$ were males and $30(15.9 \%)$ were females. This number is about $10 \%$ lower than patients admitted with AMI in Karachi $(43 \%)^{12}$. However, number of diabetics in STEMI observed in our study were almost similar to age among diabetic patients but also in age group lesser than 40 years $^{17}$. The most significant complications observed during our study were left ventricular failure, arrhythmias, cardiogenic shock and death. All these complications were more common in diabetic group. These results were almost similar to earlier study conducted in Pakistan ${ }^{18-20}$. Another study conducted in Greece, abroad showed almost similar results ${ }^{16}$. During our study post MI angina was more common in non-diabetic patients which is against other studies conducted ${ }^{21}$. Those study showed similar occurrence of these complications in both groups 22-23, therefore it needs further study to clarify about the existence of these complications in these two groups. In most studies the history showed that younger patient had first sign of heart disease one to two days back and they often ignored it and not consider themselves to be victim of heart disease at this age which leads to increase in hospital mortality in this age ${ }^{24}$.

\section{CONCLUSION}

In our study we observed that left ventricular failure and arrhythmias were the major complications. Mortality was higher in diabetic patients than non-diabetic patients. In both groups, PPCI and SK reduced mortality. Post MI angina was found more frequent in non-diabetic group. However further research in this regards 
maybe required. Moreover, it can be seen that Diabetes mellitus can cause more post-MI complications in our population as compared to those in non-diabetic patients; therefore it is also important to decrease its incidence, as it is a modifiable risk factor.

\section{CONFLICT OF INTEREST}

This study has no conflict of interest to be declared by any author.

\section{REFERENCES}

1. Bajzer СТ. Acute myocardial infarction. In: Medicine index. Cleve Clin J Med 2002; 1(1): 222-26.

2. Van't Hof AW, Liem A, de Boer MJ, Zijlstra F. Clinical value of 12-lead electrocardiogram after successful reperfusion therapy for acute myocardial infarction. Zwolle Myocardial infarction Study Group. Lancet 1997; 350(9078): 615-19.

3. Schröder R. Prognostic impact of early st-segment resolution in acute S Televation myocardial infarction. Circulation 2004; 110(21): 506-10.

4. E-Lemos JA, Braunwalo E. ST segment resolution as a tool for assessing the efficacy of reperfusion therapy. J Am Coll Cardiol 2001; 38(5): 1283-94.

5. Keil U, Liese AD, Hense HW, Filipiak B, Döring A, Stieber J, Löwel $\mathrm{H}$. Classical risk factors and their impact on incident nonfatal and fatal myocardial infarction and all-cause mortality in southern Germany: results from the MONICA Augsburg Cohort Study 1984-1992. Eur Heart J 1998; 19(8): 1197-207.

6. Schröder R, Dissmann R, Brüggemann $T$, Wegscheider $K$, Extent of early ST segment elevation resolution: a simple but strong predictor of outcome in patients with acute myocardial infarction. J Am Coll Cardiol 1994; 24(2): 384-91.

7. Carlsson J, Kamp U, Härtel D,. Resolution of ST-segment elevation in acute myocardial infarction - early prognostic significance after thrombolytic therapy. Results from the COBALT trial. Herz 1999; 24(6): 440-47.

8. Iqbal MJ, Javed MT, Tahira I. Complications and mortality in ST-segment elevation acute myocardial infarction in diabetic and non-diabetic patients. Med J Islamic World Acad Sci 2011; 109(412): 1-8.

9. Woodfield SL, Lundergan CF, Reiner JS, Greenhouse SW, Thompson MA, Rohrbeck SC, et al. Angiographic findings and outcome in diabetic patients treated with thrombolytic therapy for acute myocardial infarction: the GUSTOI experience. J Am Coll Cardiol 1996; 28(7): 1661-69.

10. Mak KH, Moliterno DJ, Granger CB, Miller DP, White HD, Wilcox HD, et al. Influence of diabetes mellitus on clinical outcome in the thrombolytic era of acute myocardial infarction. GUSTO-I Investigators. global utilizations of streptokinase and tissue plasminogen activator for occluded coronary arturs. J Am Coll Cardiol 1997; 30(1): 171-79.
11. Ishihara $M$, Sato $H$, Kawagoue $T$, Shimatani $Y$, Kurisu $S$, Nishioka $K$, et al. Impact of diabetes mellitus on long-term survival after acute myocardial infarction in patients with single vessel disease. Heart 2001; 86(1): 133-38.

12. Zairis MN, Lyras AG, Makrygiannis SS, Psarogianni PK, Adampoulou EN, Handanis SM, et al. Type 2 diabetes and intravenous thrombolysis outcome in the setting of ST elevation myocardial infarction. Diabetes Care 2004; 27(1): 967-71.

13. Hasdai D, Granger CB, Srivatsa SS, Crigor DA, Ellis SG, Gliff $\mathrm{RM}$, et al. Diabetes mellitus and outcome after primary coronary angioplasty for acute myocardial infarction: lessons from the GUSTO-IIb Angioplasty Substudy. Global Use of Strategies to Open Occluded Arteries in Acute Coronary Syndromes. J Am Coll Cardiol 2000; 35(6): 1502-12.

14. Devlin W, Cragg D, Jacks M, Friedman H, O'Neill W, Grines C. Comparison of outcome in patients with acute myocardial infarction aged $>75$ years with that in younger patients. Am J Cardiol 1995; 75(8): 573-76.

15. Czyzk A, Krolewski AS, Szablowska S, A lot A, Kopczynski J, et al. Clinical course of myocardial infarction among diabetic patients. Diabetes Care 1980; 3(4): 526-29.

16. Timmer JR, Ottervanger JP, De boer M, Bocrsma E, Grines CL, Westerhout CM. Primary percutaneous coronary intervention compared with fibrinolysis for myocardial infarction in diabetes mellitus: result from the primary coronary angioplasty vs thrombolyis-2 trial. Arch Intern Med 2007; 167(1): 1353-59.

17. McGill JB, Schneider DJ, Arfken CL, Lucore CL, Sopel BG. Factors responsible for impaired fibrinolysis in obese subjects and NIDDM patients. Diabetes 1994; 43(1): 104-09.

18. Tipoo FA, Quraishi AR, Najaf SM, Kazmi KA, Jafary F, Dhakam $\mathrm{S}$, Shafquat A. Outcome of cardiogenic shock complicatingacute myocardial infarction. J Coll Physicians Surg Pak 2004; 14(1): 6-9.

19. King SB. Acute myocardial infarction: are diabetics different? J Am Coll Cardiol 2000; 35(1): 1513-15.

20. UCLA Chest Pain and Acute Coronary Syndrome, Patient Management Guideline. UCLA clinical practice guideline 2005: 1-23 Available from: www.med.ucla.edu > champ > ACS05a

21. Ratcliffe AT, Pepper C. Thrombolysis or primary angioplasty? Reperfusion therapy formyocardial infarction in the UK. Postgrad Med J 2008; 84(988): 73-77.

22. Michas G, Karvelas G. Cardiovascular disease in greece; the latest evidence on risk factors. Hellenic J Cardiol 2019; 60: 271-5.

23. O'Gara PT, Kushner FG, Ascheim DD. American College of Cardiology Foundation/American Heart Association Task Force on Practice Guidelines. CCF/AHA guideline for the management of ST-elevation myocardial infarction: a report of the American College of Cardiology Foundation / American Heart Association Task Force on Practice Guidelines. Circulation 2013; 127(4): e362-425.

24. Roffi M, Patrono C, Collet JP. ESC Guidelines for the management of acute coronary syndromes in patients presenting without persistent ST-segment elevation: task force for the management of acute coronary syndromes in patients presenting without persistent ST-Segment Elevation of the European Society of Cardiology (ESC). Eur Heart J 2016; 37(3): 267-315. 